This item was submitted to Loughborough's Research Repository by the author.

Items in Figshare are protected by copyright, with all rights reserved, unless otherwise indicated.

\title{
Horizontal agreements and R\&D complementarities: merger versus RJV
}

PLEASE CITE THE PUBLISHED VERSION

http://dx.doi.org/10.1080/13571516.2015.1049848

\section{PUBLISHER}

(C) Taylor \& Francis

\section{VERSION}

AM (Accepted Manuscript)

\section{PUBLISHER STATEMENT}

This work is made available according to the conditions of the Creative Commons Attribution-NonCommercialNoDerivatives 4.0 International (CC BY-NC-ND 4.0) licence. Full details of this licence are available at: https://creativecommons.org/licenses/by-nc-nd/4.0/

\section{LICENCE}

CC BY-NC-ND 4.0

\section{REPOSITORY RECORD}

Ferrett, Benjamin E., and Joanna Poyago-Theotoky. 2019. "Horizontal Agreements and R\&D Complementarities: Merger Versus RJV". figshare. https://hdl.handle.net/2134/21781. 


\title{
Horizontal Agreements and R\&D Complementarities: Merger versus $\mathrm{RJV}^{*}$
}

\author{
Ben Ferrett ${ }^{\dagger}$ \\ School of Business and Economics, Loughborough University \\ GEP, University of Nottingham \\ Joanna Poyago-Theotoky \\ Department of Economics and Finance, La Trobe University \\ Rimini Centre for Economic Analysis (RCEA)
}

${ }^{*}$ We thank the Editor and an anonymous referee for their helpful comments and suggestions.

†School of Business and Economics, Loughborough University, Epinal Way, Loughborough, LE11 3TU, Leicestershire, UK.

E-mail: B.E.Ferrett@lboro.ac.uk

Tel:+44 (0)1509 222712

${ }^{\ddagger}$ Corresponding author:

Department of Economics and Finance, La Trobe University, Melbourne, Vic 3086, Australia.

E-mail: j.poyago-theotoky@latrobe.edu.au

Tel:+61 (0)394791409 


\begin{abstract}
We study the decision of two firms within an oligopoly concerning whether to enter into a horizontal agreement to exploit complementarities between their R\&D activities and if so, whether to merge or form a research joint venture (RJV). In contrast to horizontal merger and motivated by real-world evidence, we incorporate a probability that an RJV contract will fail to enforce R\&D sharing. We find that a horizontal agreement always arises in equilibrium, which is consistent with empirical findings that $\mathrm{R} \& \mathrm{D}$ complementarities between firms positively influence the formation of horizontal agreements. The insiders merger/RJV choice involves a trade-off: While merger offers certainty that $\mathrm{R} \& \mathrm{D}$ complementarities will be exploited, it leads to a profit-reducing reaction by outsiders on the product market, where competition is Cournot. Greater contract enforceability (quality) and $\mathrm{R} \& \mathrm{D}$ investment costs both favour RJV. Interestingly, the insiders may choose to merge even when RJV contracts are always enforceable, and they may opt to form an RJV even when the likelihood of enforceability is negligible. We also explore the welfare implications of the firms merger/RJV choice.
\end{abstract}

Keywords: horizontal merger, research joint venture (RJV), contract enforceability, process $R \& D, R \& D$ complementarity.

JEL numbers: O30, L13, D43 


\section{Introduction}

Within an industry, there are often complementarities between rival firms $R \& D$ activities, in the sense that their research efforts are not perfect substitutes. For example, Kamien et al. (1992, p.1298) characterise the R\&D process as involving trial and error (it is a multidimensional heuristic rather than a one-dimensional algorithmic process), with each firm simultaneously pursuing several avenues of research, only some of which pay off. It is thus natural that firms should seek to find methods of exploiting such R\&D complementarities to their mutual benefit.

Indeed, the empirical literature finds that R\&D complementarities between firms positively influence the formation of horizontal agreements, such as horizontal mergers and research joint ventures (RJVs). Gugler and Siebert (2007), for example, find that both mergers and RJVs in the semiconductor industry are associated with substantial efficiency gains, which they partly attribute to the internalisation of positive R\&D externalities. (See also Andrade et al. (2001) on horizontal mergers, and Hernàn et al. (2003) on RJVs.) For a survey, which finds that exploiting complementarities is a major motive for cooperation in R\&D, see Veugelers (1998).

In this paper, we examine the choice between horizontal merger and RJV in a setting where firms $R \& D$ investments are endogenous and $R \& D$ complementarities exist across firms. In an RJV, the participating firms remain independent entities who maximise their own profits, whereas decisions within a merged firm are taken to maximise joint profits. Competition policy practitioners typically argue that an RJV is socially preferred to a horizontal merger because, while both institutional structures facilitate the sharing of $R \& D$ results and the exploitation of complementarities, an RJV has the added virtue that it preserves product-market competition between the participants. Thus, merger-specific synergies resulting from R\&D complementarities are required to justify a merger (see, e.g., Farrell and Shapiro, 2001).

The model we present contains two ways in which the degree of R\&Dcomplementarity exploitation might differ between an RJV and a merger. First, in contrast to the existing literature, we allow for the possibility that 
the RJV contract might fail to enforce R\&D sharing by the insiders. This is consistent with the empirical evidence, which "suggests that cooperation carries a disturbingly high risk of failure" (Veugelers, 1998, p. 420). Second, $R \& D$ investment levels, which are endogenously determined, might differ between RJV and merger - since the positive externality of one insider's R\&D effort on the other will be internalised only in the latter case.

It seems intuitively appealing that, relative to an RJV, a horizontal merger might be more "effective" at inducing participating firms to pool their R\&D results. Within an RJV, firms, who remain independent, have a strong incentive not to reveal all of their R\&D results to their partners. RJVs attempt to address this problem through the use of contracts that are signed when RJVs are established, but such contracts might fail to be enforceable ex post (i.e. after R\&D results have been realised). Therefore, for the insiders, a horizontal merger, which precommits them to pooling R\&D outputs (through the objective of joint profit maximisation), can be an attractive alternative to forming an RJV - independently of market power considerations.

For example, in 2000, the Federal Trade Commission approved the merger between BP (then called BP Amoco) and the Atlantic Richfield Company (ARCO) partly on the grounds that, by committing the firms to sharing their accumulated technical expertise, it would significantly reduce extraction costs at the Prudhoe Bay oil field in Alaska. During the case, BP and ARCO successfully argued that over twenty years of contractual experiments to gain the benefits of information pooling had failed (Farrell and Shapiro, 2001, p. 705). Moreover, Holmström and Roberts (1998, pp. 90-91) discuss the difficulties faced by attempts to facilitate the sharing of knowledge between competing firms, concluding that "knowledge transfers are a very common driver of mergers and acquisitions". They discuss the corporate structures of $\mathrm{ABB}$, a large multinational in electrical equipment, and $\mathrm{BP}$, and show how, for both firms, integration is crucial to facilitating knowledge sharing between their constituent business units.

R\&D "verifiability" - that is, observability by courts - is a crucial element in our analysis. In advance of results emerging from the research lab, both the quantitative and the qualitative nature of $R \& D$ output are typically unknown. This makes it very tough to write an RJV contract that describes R\&D results across all possible states of the world sufficiently precisely to 
ensure that courts can always enforce its sharing rules. ${ }^{1}$ The incomplete nature of RJV contracts means that there is always a chance that any given contract, which commits the insiders to sharing certain defined R\&D outputs, will fail to be enforceable because the realised $R \& D$ results fall outside the terms of the original contract. In our model, we capture the success/failure of the RJV contract by assuming that it is enforceable with a certain probability, which we term the "contract quality". Aside from the problem of contract enforceability, the modelling of behaviour within RJVs is identical to the "RJV competition" case of Kamien et al. (1992), where RJV insiders set both their $\mathrm{R} \& \mathrm{D}$ and their output levels independently to maximise their own profits. ${ }^{2}$

By contrast, a bilateral merger reduces the number of independent firms in the industry by one, with the merged firm operating two R\&D labs due to the rising marginal cost of R\&D. Thus, merging gives the insiders a size advantage on the product market relative to the outsiders, which is empirically plausible. ${ }^{3}$

We model an oligopolistic industry, where firms compete both in process $R \& D$ and, subsequently, in output, and focus on the decision of two firms concerning whether to enter into a horizontal agreement to exploit R\&D complementarities and, if so, whether to merge or, form an RJV. Much of the structure of the model is standard to facilitate straightforward comparisons with existing results in the literature. The firms are initially identical, and the product is homogeneous. Each firm has a constant unit cost, which decreases in its own R\&D investment. ${ }^{4}$ We assume "full" R\&D complementarity, which we take to mean: a given firm's R\&D activity is as effective at reducing other firms' marginal costs as it is at reducing its own. ${ }^{5}$ Aside from $R \& D$ sharing within a merger/RJV, there are no (involuntary) inter-firm R\&D spillovers.

Surprisingly, to the best of our knowledge, the "merger versus RJV" choice has received no attention in the vast theoretical literature on the organisation of R\&D. This paper attempts to partially address this shortcoming. Existing applied theory papers on horizontal mergers and RJVs have tended to analyse the choice between a given type of horizontal agreement, either merger or RJV, and no-agreement. ${ }^{6}$ Thus, the present paper, which focusses on the merger/RJV choice, is a bridge between those two literatures. 
The paper also addresses a gap between the IO literature on RJVs (e.g. Kamien et al., 1992), which typically assumes that RJV contracts are always enforceable (while we allow for "contract failure" within the RJV), and that on incomplete contracts (especially Williamson, 1985), which often abstracts from the effects of product-market competition by assuming bilateral monopoly-type interactions between firms in unrelated (or vertically related) markets. ${ }^{7}$

A first finding (in Section 4) is that, for the two insiders, the RJV always dominates the no-agreement outcome. This implies that a horizontal agreement, either merger or RJV, will always arise in equilibrium. With identical firms, it is well established within the literature that industry profits are maximised when all firms determine their R\&D investments cooperatively, and pool R\&D results, but compete à la Cournot in outputs; ${ }^{8}$ this set-up is termed RJV cartelization by Kamien et al. (1992). In contrast, our finding relates to an RJV where R\&D investments are determined non-cooperatively and participation is limited to a subset of firms. ${ }^{9}$

Next, we invesigate the insiders' merger/RJV choice. The analysis here can be related to that of Davidson and Ferrett (2007), who examine the insiders' choice between horizontal merger and no-agreement within a similar model (but with brand heterogeneity). Merger allows the exploitation of R\&D complementarities, but it provokes a profit-reducing output expansion by the outsiders on the product market, where competition is Cournot. ${ }^{10}$ Therefore, a profitability trade-off between merger and no-agreement emerges: merger internalises R\&D complementarities but provokes a profit-reducing output expansion by the outsiders.

The RJV resembles no-agreement in that, in both scenarios, all firms in the industry make both their $\mathrm{R} \& \mathrm{D}$ and their production decisions independently to maximise their own (expected) profits. However, unlike no-agreement, the RJV does allow some probability that R\&D complementarities will be successfully exploited. This is what lies behind the finding, discussed above, that the insiders always prefer RJV to no-agreement. It thus follows that the size of the region in parameter space where merger dominates no-agreement will be larger than that where merger dominates RJV.

The insiders' merger/RJV choice entails a trade-off: while merger offers a 
higher probability than RJV that R\&D complementarities will be successfully exploited, it tends to be less profitable, ceteris paribus, ${ }^{11}$ than RJV on the product market. In product-market competition, merger suffers in comparison with RJV for the same reason that it underperforms no-agreement: the profitability of merger is undermined by the reactions of outsiders. In concentrated industries, an increase in competitive pressure (increased number of competing firms) undermines the "market power" gain from merger, and it must therefore be offset by lower "contract quality" (which makes RJV less attractive) to maintain indifference.

Finally, we derive two surprising and interesting results that relate to the extremes of contract quality. First, we show that the insiders may optimally choose to merge even when RJV contracts are "perfect" (i.e. always enforceable). We suggest that this is because the "profit externality" between the insiders in R\&D determination is internalised under HM - but not under RJV. Secondly, on the contrary, we show that the insiders may optimally choose to form an RJV even when the probability of contract enforceability is negligible.

The remainder of the paper is organised as follows. Section 2 presents the model, and Section 3 presents the equilibrium solutions for the three possible R\&D organization choices by the insiders: no-agreement, horizontal merger, and RJV. Section 4 analyses the insiders' no-agreement/merge/RJV choice, and presents a brief illustrative welfare analysis. Finally, Section 5 concludes.

\section{Model Setup}

There are $n$ (initially identical) firms producing a homogeneous good. Firm $i$ 's quantity is denoted by $q_{i}$ and $p$ is the good's price with the inverse demand function being

$$
p=1-Q
$$

where $Q=\sum_{i=1}^{n} q_{i}$ is industry output. Initially, each firm operates with the same constant unit cost, $c$, with $0<c<1$, and there are no fixed costs. There is no entry into the industry. 
For simplicity we consider a situation where two firms have two possible means of exploiting synergies between their R\&D activities: horizontal merger (HM) or research joint venture (RJV). We consider the following sequence of moves: in stage 0, the choice between NA (no agreement), HM, and RJV is made; in stage 1, all firms simultaneously choose how much to invest in process $\mathrm{R} \& \mathrm{D}$ (cost reduction); and in stage 2, all firms compete à la Cournot on the product market. We assume complete information, and we solve the game backwards to isolate its subgame perfect Nash equilibrium.

The stage 0 choice between NA, HM and RJV affects the insiders' costs and their subsequent behaviour. The NA case, where the two firms remain independent, is the easiest to consider because all the firms in the industry are symmetric. Firm $i^{\prime}$ s total cost of $\mathrm{R} \& \mathrm{D}$ is $(\gamma / 2) x_{i}^{2}$, where $\gamma$ is a constant capturing the difficulty (or efficiency) of R\&D. Under NA, this R\&D expenditure lowers a firm's unit cost to $c-x_{i}$, where $x_{i}$ represents $\mathrm{R} \& \mathrm{D}$ effort (cost reduction). ${ }^{12}$

Under HM, the subsequent R\&D and output decisions of the merged firm are made to maximise joint profits. Horizontal merger guarantees that R\&D complementarities are fully exploited: the merged firm owns (two R\&D labs and) two plants with equal unit costs. The merged firm is therefore indifferent concerning how to divide its total output between its two plants. ${ }^{13}$

Assume, for simplicity, that firm 1 merges with firm $n$ to become firm $m .^{14}$ Denote the total cost reduction that the merged firm generates through R\&D (at both of its labs) by $x_{m}$. Therefore, its unit cost is $c_{m}=c-x_{m}$. Because the merged firm owns two R\&D labs (and given decreasing returns to $R \& D$ ), it will optimally generate half of its total cost reduction at each lab (i.e. it will divide its total R\&D budget equally between its two labs). Therefore, the merged firm (firm $m$ ) has a total R\&D cost of $2\left(\frac{\gamma}{2}\right)\left(\frac{x_{m}}{2}\right)^{2}=\left(\frac{\gamma}{4}\right) x_{m}^{2}$. The remaining firms (outsiders) behave like the firms in the NA case.

For concreteness, suppose firms 1 and 2 form the RJV (although since all firms are initially identical, this assumption is innocuous: it just eases the expression of some of the expressions in the next section). For a given industry cost vector, the Cournot equilibrium is the same as in the NA game. 
Under RJV, the participant firms (1 and 2) agree in a contract, signed before $R \& D$ investments are decided, to share their $R \& D$ results before the start of stage 2 (product market competition). However, after R\&D results have been realised, this contract turns out to be enforceable only with probability $\omega$, which measures "contract quality". Thus, $\omega$ can also be interpreted as the probability that R\&D outputs are observable by courts, or "verifiable" ${ }^{15}$ In a nutshell, the problem is that the RJV contract, written in advance of $R \& D$ activity being undertaken, cannot exhaustively and precisely catalogue R\&D output in every possible state of the world. Such breadth of coverage is necessary, however, because RJV insiders have a strong incentive not to share their research outputs. We will sometimes refer to contract enforceability as "RJV success" and to contract unenforceability as "RJV failure", and we assume that RJV success/failure becomes common knowledge.

If, in the light of the insiders' R\&D outputs, the RJV contract turns out to be unenforceable (with probability $1-\omega$ ), then the RJV insiders have a dominant strategy not to share their $R \& D$ results (because they can do so with impunity) and their unit cost functions in stage 2 are as under NA, e.g. $c_{1}=c-x_{1}$. Alternatively, if the RJV contract turns out to be enforceable, then it will ensure that the insiders pool their R\&D results and the insiders' unit cost functions in stage 2 will be as under HM, e.g., $c_{1}=c-x_{1}-x_{2}$.

In the RJV scenario, all firms (both insiders and outsiders) make both their R\&D and their output choices independently to maximize their own expected profits (outsiders, of course, have access only to their own R\&D results), ${ }^{16}$ and all firms are risk neutral. 


\section{Equilibrium Solutions}

\subsection{No agreement between firms (NA)}

The profit of firm $i$ is given by $\pi_{i}=\left[p-\left(c-x_{i}\right)\right] q_{i}-\frac{\gamma}{2} x_{i}^{2}$. Stage 2 Cournot competition yields the following output levels:

$$
\begin{aligned}
q_{i} & =\frac{1+c_{-i}-n c_{i}}{1+n}=\frac{(1-c)+(n+1) x_{i}-\sum_{j=1}^{n} x_{j}}{n+1} \\
Q & =\frac{n-\sum_{1}^{n} c_{i}}{1+n}=\frac{n(1-c)+\sum_{j=1}^{n} x_{j}}{n+1}
\end{aligned}
$$

where, as is usual, $c_{-i}$ denotes the sum of the unit costs of firm $i$ 's rivals.

In stage $1, x_{i}$ is set to maximise $\Pi_{i}=q_{i}^{2}-\frac{\gamma}{2} x_{i}^{2}$. Imposing symmetry $\left(x_{i}=x_{N A}\right.$ $\forall i$ ) on the resulting $\mathrm{FOC}$ and solving gives

$$
x_{N A}=\frac{2 n(1-c)}{\gamma(1+n)^{2}-2 n}
$$

as the equilibrium level of R\&D output. ${ }^{17}$ Note that (i) $d x_{N A} / d n<0$ which proves that a pairwise merger (a reduction in the number of firms, see below) results in an increase in $\mathrm{R} \& \mathrm{D}$ and (ii) $d x_{N A} / d \gamma<0$. Effectively a merger will reduce competition amongst firms and increases each firm's market share leading to an increased incentive for cost-reducing $\mathrm{R} \& \mathrm{D}$. The common equilibrium level of profits, $\Pi_{N A}$, can be found by substituting (3) into (2) and using $\Pi_{i}=q_{i}^{2}-\frac{\gamma}{2} x_{i}^{2}$, which is:

$$
\Pi_{N A}=\frac{\gamma(1-c)^{2}\left[\gamma(1+n)^{2}-2 n^{2}\right]}{\left[\gamma(1+n)^{2}-2 n\right]^{2}}
$$




\section{$3.2 \quad$ Horizontal merger (HM)}

In stage 2 (output stage) we obtain the following values in Cournot equilibrium:

$$
\begin{aligned}
& q_{i}=\frac{1+\sum_{j=1}^{n-1} c_{j}-n c_{i}}{n}=\frac{(1-c)+n x_{i}-\sum_{j=1}^{n-1} x_{j}}{n} \\
& Q=\frac{(n-1)-\sum_{i=1}^{n-1} c_{i}}{n}=\frac{(n-1)(1-c)+\sum_{j=1}^{n-1} x_{j}}{n}
\end{aligned}
$$

In the R\&D stage, firm $m$ chooses $x_{m}$ to maximise $q_{m}^{2}-\frac{\gamma}{4} x_{m}^{2}$, subject to $c_{m}=c-x_{m}$; and outsider $j$ chooses $x_{j}$ to maximise $q_{j}^{2}-\frac{\gamma}{2} x_{j}^{2}$, subject to $c_{j}=c-x_{j}$. Imposing symmetry $x_{j}=x_{m o}$ for all the outsiders on the resulting FOCs, and solving, ${ }^{18}$ yields:

$$
\begin{aligned}
x_{m} & =\frac{m_{2}\left(n-2+m_{1}\right)}{m_{1}+m_{2}(n-2)}(1-c) \\
x_{m o} & =\frac{m_{2}-1}{m_{1}+m_{2}(n-2)}(1-c)
\end{aligned}
$$

where

$$
\begin{aligned}
& m_{1}=\frac{4(n-1)-\gamma n^{2}}{2(n-1)} \\
& m_{2}=\frac{4(n-1)}{\gamma n^{2}-4(n-1)^{2}} .
\end{aligned}
$$

Therefore the merged firm's equilibrium profits under HM are

$$
\Pi_{m}=\left(\frac{1-c+(n-1) x_{m}-(n-2) x_{m o}}{n}\right)^{2}-\frac{\gamma}{4} x_{m}^{2}
$$


and upon substituting from above becomes

$$
\Pi_{m}=\frac{\left.\gamma(1-c)^{2}\left[n^{2}(\gamma-4)+8 n-4\right)\right][n(\gamma-2)+2]^{2}}{\left[8-16 n+n^{3}(\gamma-4) \gamma+4 n^{2}(2+\gamma)\right]^{2}} .
$$

For the insider firms, HM will dominate NA if and only if

$$
\Pi_{m}>2 \Pi_{N A} .
$$

\subsection{Research Joint Venture (RJV)}

The RJV comprises firms 1 and 2. Unit costs depend on R\&D investments in stage 1 and also on whether the RJV succeeds or fails. Stage 2 under RJV is qualitatively identical to stage 2 under NA; see (2) above. In stage 1 under RJV, firm 1 chooses $x_{1}$ to maximize expected profits:

$$
\begin{aligned}
\Pi_{r j v}^{i n, 1}= & \omega\left(\frac{1-(n-1)\left(c-x_{1}-x_{2}\right)+\sum_{j=3}^{n}\left(c-x_{j}\right)}{n+1}\right)^{2} \\
& +(1-\omega)\left(\frac{1-n\left(c-x_{1}\right)+\left(c-x_{2}\right)+\sum_{j=3}^{n}\left(c-x_{j}\right)}{n+1}\right)^{2}-\frac{\gamma}{2} x_{1}^{2},
\end{aligned}
$$

with an analogous expression holding for firm 2. An RJV outsider (here, firm 3) chooses $x_{3}$ to maximise

$$
\begin{aligned}
\Pi_{r j v}^{\text {out }, 3}= & \omega\left(\frac{1+2\left(c-x_{1}-x_{2}\right)-n\left(c-x_{3}\right)+\sum_{j=4}^{n}\left(c-x_{j}\right)}{n+1}\right)^{2} \\
& +(1-\omega)\left(\frac{1+\left(c-x_{1}\right)+\left(c-x_{2}\right)-n\left(c-x_{3}\right)+\sum_{j=4}^{n}\left(c-x_{j}\right)}{n+1}\right)^{2}-\frac{\gamma}{2} x_{3}^{2}
\end{aligned}
$$


with similar expressions holding for the remaining outsider firms. Imposing symmetry $\left(x_{1}=x_{2}=x_{r j v}^{i n}\right.$ and $x_{j}=x_{r j v}^{\text {out }}$ for all the outsiders $)$ on the resulting FOCs, and solving, ${ }^{19}$ we get:

$$
\begin{aligned}
x_{r j v}^{\text {in }} & =\frac{(n-2) r_{1}-1}{2(1+\omega)(n-2) r_{1}+r_{2}}(1-c) \\
x_{r j v}^{\text {out }} & =\frac{\left[2(1+\omega)+r_{2}\right] r_{1}}{2(1+\omega)(n-2) r_{1}+r_{2}}(1-c)
\end{aligned}
$$

where

$$
\begin{aligned}
r_{1} & =\frac{2 n}{\gamma(1+n)^{2}-6 n} \\
r_{2} & =\frac{2(n-1)[n(1+\omega)-2 \omega]-\gamma(1+n)^{2}}{2(n-\omega)} .
\end{aligned}
$$

Therefore, we can express an RJV insider's equilibrium profits as:

$$
\begin{aligned}
\Pi_{r j v}^{i n} & =\omega\left(\frac{1-c+2(n-1) x_{r j v}^{i n}-(n-2) x_{r j v}^{o u t}}{1+n}\right)^{2} \\
& +(1-\omega)\left(\frac{1-c+(n-1) x_{r j v}^{i n}-(n-2) x_{r j v}^{o u t}}{1+n}\right)^{2}-\frac{\gamma}{2}\left(x_{r j v}^{i n}\right)^{2},
\end{aligned}
$$

which, after the relevant subtitutions yields:

$$
\Pi_{r j v}^{i n}=\frac{(1-c)^{2}[n(\gamma-2)+\gamma]^{2}\left[\gamma(1+n)^{2}-2(n-1)^{2} \omega\right]\left[\gamma+2(\omega-1) \omega+n^{2}(\gamma-2+2 \omega)+2 n(\gamma-2(\omega-1) \omega)\right]}{\left\{(1+n)[n(\gamma-2)+\gamma]\left[\gamma(1+n)^{2}-2 n\right]-2(n-2)(n-1)\left[(1+n)^{2} \gamma-2 n\right] \omega+8 n(n-2) \omega^{2}\right\}^{2}}
$$

We can obtain a similar expression for the equilibrium profits for an RJV outsider by substituting from (7) and (8). 


\section{Analysis and Results}

\subsection{RJV dominates $N A$}

For the insiders, RJV dominates NA in the sense that $\Pi_{r j v}^{i n} \geq \Pi_{N A}$ for all parameter values, with strict inequality if $\omega \neq 0$. The following proposition elaborates.

Proposition 1 The insiders strictly prefer participating in an RJV to No Agreement, unless the $R J V$ is guaranteed to fail. In particular: (i) for $\omega=$ $0, \Pi_{r j v}^{i n}=\Pi_{N A}$, (ii) for $\omega=1, \Pi_{r j v}^{i n}>\Pi_{N A}$ and (iii) for $0<\omega<1, \Pi_{r j v}^{i n}>$ $\Pi_{N A}$.

The proof of the proposition is in the Appendix. However, we provide here an intuitive explanation: Note that if $\omega$ equals zero (i.e. the RJV contract is guaranteed to fail), then the RJV game is identical to the NA game (this explains part (i)). When $\omega$ is strictly positive, the RJV contract may prove successful. Suppose, first, that every firm's R\&D level is fixed at $x_{N A}$ and that only outputs can be varied. If, in this situation, two firms enter into a contract to pool their R\&D stocks (as in an RJV), then their marginal costs will fall with probability $\omega$ and their expected profits will rise as, if the RJV succeeds, they expand on the product market at the expense of the $n-2$ outsiders. Next, allow $\mathrm{R} \& \mathrm{D}$ levels to vary. The rise in insider output just described increases the "marginal benefit" (or marginal variable profit) to an insider since cost reductions are now spread over a larger quantity of production. Hence, both insider R\&D investment and insider profits rise. The response of outsiders to higher R\&D investment by the firms in the RJV is to retrench: they are squeezed on the product market, and cut their R\&D levels. In turn, this reaction by the outsiders benefits the insiders. It is clear that ceteris paribus (specifically, holding the $R \& D$ levels of outsiders fixed) the insiders would benefit from the move from NA to RJV. Our argument has sought to show that the reaction of outsiders - specifically, the fact that they cut $R \& D$ investment in response to being squeezed on the product market following the formation of an RJV - is also beneficial to the insiders. 
Finally, note that we have assumed that firms' non-R\&D fixed costs are independent of the NA/HM/RJV choice. However, this might not be the case. If, for example, there were even an infinitesimal fixed cost of implementing a horizontal agreement (either RJV or HM), then NA would dominate RJV if $\omega$ is sufficiently small.

On the contrary, of course, both RJV and (especially) HM might present opportunities for savings in non-R\&D fixed costs through the avoidance of duplication (e.g. the sharing of "back office" facilities) and "synergies". Such savings are a further reason for dropping NA from the equilibrium analysis.

\subsection{HM versus RJV: the central trade-off}

The result of Proposition 1 that RJV is always more profitable for the insiders than NA greatly simplifies the analysis by allowing us to drop the NA case. The equilibrium choice is now between HM and RJV.

In the present model, RJV resembles NA in that, in both scenarios, all firms in the industry make both their R\&D and their production decisions independently to maximise their own (expected) profits. However, unlike NA, RJV does allow some probability, $\omega$, that R\&D complementarities will be exploited. This is what lies behind the result in Proposition 1 that the insiders always prefer RJV to NA. To fully explore the choice of horizontal agreement we proceed by examining the profit difference $\Pi_{m}-2 \Pi_{r j v}^{i n} \equiv \Delta \Pi_{m r}$. As is often the case in models of multi-stage competition such as the present one, the complexity of the equilibrium solutions means that an analytical proof is, unfortunately, beyond reach. However, we have obtained numerical solutions and results that are robust to changes in the relevant parameter values. ${ }^{20} \mathrm{In}$ the numerical results we present we have set $c=0.3$; varying $c$ does not change the results in any qualitative manner as it is just a scaling parameter. However, we do vary the remaining parameters of the model, namely $n$ (the number of firms), $\omega$ (the contract quality) and $\gamma$ (efficiency/difficulty of R\&D, where $\gamma>4$ so as to satisfy all relevant second-order conditions).

Figure 1 depicts the choice between HM and RJV, and the way in which the intensity of market competition as captured by the number of firms in 
Figure 1: The insiders' choice between HM and RJV

\section{Figure 1 goes here}

the market, $n$, may be traded off against contract quality, $\omega$, to maintain indifference on the part of the insiders. ${ }^{21}$ The line in Figure 1 is the "indifference locus" such that $\Pi_{m}-2 \Pi_{r j v}^{i n}=0$ (or $\Delta \Pi_{m r}=0$ ); above the line the insiders' preferred horizontal agreement is RJV $\left(\Delta \Pi_{m r}<0\right)$ and below it is $\mathrm{HM}\left(\Delta \Pi_{m r}>0\right)$.

There is 'perfect' R\&D complementarity in our model, in the sense that there is zero duplication between the insiders' R\&D activities, so that within a successful RJV a given firms R\&D investment reduces both insiders unit costs by the same amount. Figure 1 highlights that, even with such 'perfect' complementarity, it is still possible for the insiders to prefer RJV to HM despite $\omega<1$.

Note that for small $n$, i.e., concentrated industries, our primary focus, the 'indifference locus' is downward sloping. Intuitively, we justify this as follows: a higher number of competing firms undermines the 'market power' gain associated with merging, and it must therefore be offset by a lower $\omega$ (which makes the RJV less attractive) to maintain indifference. However, for quite large $n$ and low $\gamma$ the 'indifference locus' is not downard sloping (e.g., $\gamma=4$ and $n \geq 8$ ) but is essentially flat over the relevant range. Interestingly, we find that HM can dominate RJV even if contracts are perfect $(\omega=1)$, e.g., the point $(3,1)$ lies beneath the indifference locus for $\gamma=4$. In this case R\&D is relatively easy, making the 'profit externality' between the insiders in R\&D setting quite large: hence, HM (which internalises that externality) is preferred by the insiders to RJV (which doesn't). Surprisingly, RJV can dominate HM even if its chance of success is negligible ( $\omega$ close to zero), e.g., the point $(5,0)$ is above the indifference locus for $\gamma=7$. In this case $R \& D$ is relatively difficult and coupled with the strong product-market interactions makes HM unprofitable.

Figure 2 conveys a similar message to Figure 1 by showing the equivalent profit surfaces (HM and RJV): (i) a rise in $n$ undermines the 'market power' 
Figure 2: Equilibrium Profits

Figure 2 goes here

gain of the merger and (ii) more costly $\mathrm{R} \& \mathrm{D}$ (a rise in $\gamma$ ) makes RJV more profitable. Intuitively, relative to RJV, the gain from merging is that R\&D will definitely be shared, whereas the cost from merging is the reaction of outsiders on the product market (as in Salant et al. (1983)). When $\gamma$ rises, then equilibrium R\&D levels fall, so the gain from merging (rather than forming an RJV) is smaller - but there is still a Salant-type cost from merging.

\subsection{Social Welfare}

In this section we briefly explore the normative properties of the model. As usual, welfare is expressed as gross surplus less total costs (production and $\mathrm{R} \& \mathrm{D}$ costs),

$$
\begin{aligned}
W & =\int_{0}^{Q} p \cdot d Q-\sum_{i=1}^{n} c_{i} q_{i}-\frac{\gamma}{2} \sum_{i=1}^{n} x_{i}^{2} \\
& =Q-\frac{1}{2} Q^{2}-\sum_{i=11}^{n} c_{i} q_{i}-\frac{\gamma}{2} \sum_{i=1}^{n} x_{i}^{2}
\end{aligned}
$$

where where $Q \equiv \sum_{i=1}^{n} q_{i}$, and $i$ indexes plants. ${ }^{22}$

In the NA equilibrium, where all firms are identical, (10) after the necessary substitutions yields:

$$
W_{N A}=\frac{(1-c)^{2} n \gamma\left[(1+n)^{2}(2+n) \gamma-4 n^{2}\right]}{2\left[(1+n)^{2} \gamma-2 n\right]^{2}} .
$$

In HM, applying (10) and accounting for the asymmetry between insiders and outsiders results in: 


$$
\begin{aligned}
W_{m} & =2 q_{m}\left(1-c+x_{m}\right)+(n-2) q_{m o}\left(1-c+x_{m o}\right) \\
& -\frac{1}{2}\left[2 q_{m}+(n-2) q_{m o}\right]^{2}-\frac{\gamma}{2}\left[x_{m}^{2}+(n-2) x_{m o}^{2}\right],
\end{aligned}
$$

which after the relevant substitutions and some manipulations results in the following expression for equilibrium social welfare:

$$
W_{m}=\frac{(1-c)^{2}(n-1) \gamma\left[n^{4}(1+n) \gamma^{3}-8 n^{3}\left(n^{2}-2\right) \gamma^{2}+4 n\left(n\left(29-25 n+4 n^{3}\right)-8\right)-32(n-1)^{3}\left(n^{2}-2\right)\right]}{\left[2(8+n(n(8+(4+n(\gamma-4)) \gamma)-16)]^{2}\right.} .
$$

In the case of the RJV, quantities (and profits) depend on whether the RJV is successful or not. Using (10) we obtain:

$$
\begin{aligned}
W_{r j v}= & \omega . \\
& {\left[2 q_{r j v, s}^{i n}\left(1-c+2 x_{r j v}^{i n}\right)+(n-2) q_{r j v, s}^{o u t}\left(1-c+x_{r j v}^{\text {out }}\right)-\frac{1}{2}\left[2 q_{r j v, s}^{i n}+(n-2) q_{r j v, s}^{\text {out }}\right]^{2}\right] } \\
& +(1-\omega) . \\
& {\left[2 q_{r j v, f}^{i n}\left(1-c+x_{r j v}^{i n}\right)+(n-2) q_{r j v, f}^{\text {out }}\left(1-c+x_{r j v}^{\text {out }}\right)-\frac{1}{2}\left[2 q_{r j v, f}^{i n}+(n-2) q_{r j v, f}^{\text {out }}\right]^{2}\right] } \\
& -\frac{\gamma}{2}\left[2\left(x_{r j v}^{i n}\right)^{2}+(n-2)\left(x_{r j v}^{\text {out }}\right)^{2}\right]
\end{aligned}
$$

where, $q_{r j v, s}^{i n}$ and $q_{r j v, s}^{\text {out }}$ are quantities if the RJV succeeds $(s)$ :

$$
\begin{aligned}
& q_{r j v, s}^{\text {in }}=\frac{(1-c)+2(n-1) x_{r j v}^{\text {in }}-(n-2) x_{r j v}^{\text {out }}}{1+n} \\
& q_{r j v, s}^{\text {out }}=\frac{(1-c)-4 x_{r j v}^{\text {in }}+3 x_{r j v}^{\text {out }}}{1+n}
\end{aligned}
$$

and $q_{r j v, f}^{i n}$ and $q_{r j v, f}^{\text {out }}$ are quantities if the RJV fails $(f)$ :

$$
\begin{aligned}
q_{r j v, f}^{\text {in }} & =\frac{(1-c)+(n-1) x_{r j v}^{\text {in }}-(n-2) x_{r j v}^{\text {out }}}{1+n} \\
q_{r j v, f}^{\text {out }} & =\frac{(1-c)-2 x_{r j v}^{\text {in }}+3 x_{r j v}^{\text {out }}}{1+n} .
\end{aligned}
$$


Figure 3: Equilibrium Welfare

\section{Figure 3 goes here}

Figure 4: Social preference between HM and RJV

\section{Figure 4 goes here}

The explicit expression for $W_{r j v}$ is given in the appendix.

Our first finding is that, socially, RJV always dominates NA (see Figure 3); that is, $W_{r j v}>W_{N A}$ for every set of parameter values. This finding is analogous to the result we derived in section 4.1 above on the ranking of insiders' profits, and it is unsurprising because an RJV allows R\&D complementarities to be exploited without reducing the number of independent firms on the product market.

Next, we compare the social welfare performance of RJV and HM (consider Figures 3 and 4). A rise in $\omega$ increases the relative attractiveness of RJV for given $\gamma$; as $\gamma$ increases the relative attractiveness of RJV becomes more prevalent, $W_{r j v}>W_{m}$. This conforms to a standard view amongst competition-policy practitioners: RJV is to be socially preferred to horizontal merger because it preserves product-market competition. ${ }^{23}$ However, there are always areas where HM is preferred, this occurs typically for lower $\omega$. One interpretation of this result is that poor contract quality makes the gains from a horizontal agreement "merger-specific" (in the sense of Farrell and Shapiro,2001).

Figure 4 depicts the social preference between HM and RJV, and the way in which the intensity of market competition as captured by the number of firms in the market, $n$, may be traded off against contract quality, $\omega$, to maintain indifference on the part of society. The line in Figure 4 is the "social indifference locus" such that $W_{m}-W_{r j v}=0$ (or $W_{m r}=0$ ); above the line society prefers RJV $\left(\Delta W_{m r}<0\right)$ and below it society prefers HM $\left(\Delta W_{m r}>0\right)$. Often, but not always, the 'social indifference loci' are downard 
sloping. We find that, from a social perspective, an increase in $n$ favours RJV over HM. Given this, the negative slopes in Figure 4 are not surprising: the rise in $n$ (which favours RJV) must be offset by a fall in $\omega$ (which favours $\mathrm{HM})$.

Figure 5: HM/RJV preferences of insiders and society

\section{Figure 5 goes here}

Finally, we compare the private incentives of the insiders with the social preference between HM and RJV (see Figure 5). The graphs in Figure 5 compare, for three different values of $\gamma$, the HM/RJV preferences of the insiders versus society. When $\gamma$ is small $(\gamma=4)$, we can unambiguously (i.e. for all $n$ ) say that the insiders preference for merger is stronger than society's. This is indicated by the shaded area where there is a conflict between insiders, preferring HM, and society, preferring RJV (type A conflict: HM occurs too often). This doesn't seem surprising: for example, ceteris paribus (which includes cost reductions), we expect consumers to prefer RJV to HM. Results are more complicated for larger $\gamma(\gamma=5.5$ and 7$)$. Here, the relevant indifference loci cross, so that for small $n$ the insiders are too likely to merge (from a social perspective), whereas for large $n$ they are not likely enough to merge (type B conflict: RJV occurs too often). There is a divergence in incentives here - desirability preferences differ. In all cases, the areas of conflict point to the potential for policy intervention in the direction of establishing the outcome most preferred by society.

\section{Conclusion and Discussion}

Empirical research suggests that R\&D complementarities between firms positively influence the formation of horizontal agreements. The key contribution of this paper is to examine the choice between horizontal merger and RJV as alternative vehicles for exploiting R\&D complementarities, whereas most existing contributions examine just one of those forms of horizontal agreement

in isolation. Moreover, an innovation in our modelling structure is that we 
allow for the possibility that RJV contracts might be unenforceable, which is motivated by real-world evidence that suggests that cooperation [between firms] carries a disturbingly high risk of failure (Veugelers, 1998, p. 420).

Our key findings are summarised as follows:

1. For the two insiders, RJV always dominates no-agreement, so some form of horizontal agreement (merger or RJV) always arises in equilibrium. This is consistent with the empirical findings that the presence of R\&D complementarities promotes the formation of horizontal agreements.

2. Merger/RJV tradeoff: While merger offers certainty that R\&D complementarities will be successfully exploited, it leads to an aggressive and profit-reducing reaction by outsiders on the product market. Rises in contract quality and R\&D costs favour RJV over merger.

3. Interestingly, the insiders may choose to merge even when RJV contracts are always enforceable, and they may opt to form an RJV even when the likelihood of enforceability is negligible.

4. The welfare results (where we compare the HM/RJV preference of the insiders and society) indicate that there are cases where the insiders choose to merge too often from a social point of view; however, we also found cases where the insiders choose RJV when society prefers merger. The former result is consistent with conventional wisdom amongst competition policy practitioners, whereas the latter finding, which arises because poor contract quality in the RJV makes the gains from a horizontal agreement merger-specific, challenges it.

To close, we briefly consider possible generalisations of our analysis.

The first avenue for generalisation involves considering additional vehicles for exploiting R\&D complementarities. Given that the insiders intend to pool their $R \& D$ results, there are, in principle, four distinct ways in which they could manage their R\&D and output decisions. Our analysis has considered two of these: RJV, where the insiders choose their R\&D and production 
levels independently of each other to maximise their own profits; and horizontal merger, where the R\&D and output decisions of inside brands are co-ordinated to maximise joint profits.

However, there are two other potential set-ups that the insiders could adopt. The first involves collusion in R\&D but competition in outputs. Kamien et al. (1992) refer to this as "RJV cartelization", and it might conceivably be achieved in two ways: the RJV insiders could contract all of their R\&D activities out to a third party with instructions to maximise joint profits; or they could merge and implement "divisionalization" (in the sense of Baye et al., 1996) on the product market. For our purposes, it is important to note that both of these approaches might well involve their own significant contractual problems. ${ }^{24}$ However, setting these to one side, we conjecture that such "RJV cartelization", if successfully implemented, would always dominate our RJV option. Secondly, the insiders might compete in R\&D but collude in outputs - the "semi-collusion" case of Fershtman and Gandal (1994), and Brod and Shivakumar (1999). In the Cournot setting, where mergers for market-power reasons alone are generally unprofitable, we conjecture that the insiders will prefer our RJV option to such "semi-collusion".

Secondly, we could allow for endogenous RJV and merger size, rather than restricting horizontal agreements to just two participants. In comparison with the no-agreement outcome, where all firms remain independent, it seems likely that, if legally permitted, an RJV would expand to include the entire industry. However, it is unclear whether the same is true of a horizontal merger of variable size (because merger tends to make the insiders less aggressive on the product market, which benefits outsiders). Thus, it is possible that the optimal RJV and the optimal merger would include different numbers of insiders.

The systematic investigation of these conjectures remains a task for future work. 


\section{References}

[1] Andrade, Gregor, Mark Mitchell, and Erik Stafford. "New Evidence and Perspectives on Mergers." Journal of Economic Perspectives 15, no. 2 (2001): 103-120.

[2] Bartolini, David. Investment and Merging as an Endogenous Coalition Formation Game. No. 628. Essex Discussion Paper, 2011.

[3] Bhattacharya, Sudipto, Jacob Glazer, and David EM Sappington. "Licensing and the Sharing of Knowledge in Research Joint Ventures." Journal of Economic Theory 56, no. 1 (1992): 43-69.

[4] Baye, Michael R., Keith J. Crocker, and Jiandong Ju. "Divisionalization, Franchising, and Divestiture Incentives in Oligopoly." The American Economic Review 86, no.1 (1996): 223-236.

[5] Bertrand, Olivier, Katariina Nilsson Hakkala, Pehr-Johan Norbäck, and Lars Persson. "Should Countries block foreign Takeovers of R\&D Champions and promote Greenfield Entry?." Canadian Journal of Economics/Revue canadienne d'conomique 45, no. 3 (2012): 1083-1124.

[6] Brod, Andrew, and Ram Shivakumar. "Advantageous Semi-Collusion." The Journal of Industrial Economics 47, no. 2 (1999): 221-230. 
[7] Cabolis, Christos, Constantine Manasakis, and Emmanuel Petrakis. Horizontal Mergers and Acqusitions with Endogenous Efficiency Gains. BENETeC Working Paper No. 0817. 2008. University of Crete.

[8] d'Aspremont, Claude, and Alexis Jacquemin. "Cooperative and Noncooperative R\& D in Duopoly with Spillovers." The American Economic Review 78, no.5 (1988): 1133-1137.

[9] Davidson, C. and Ferrett, B. "Mergers in Multidimensional Competition." Economica 74, no.296 (2007): 695-712.

[10] Deneckere, Raymond, and Carl Davidson. "Incentives to form Coalitions with Bertrand Competition." The RAND Journal of Economics 16, no.4 (1985): 473-486.

[11] Farrell, Joseph, and Carl Shapiro. "Scale Economies and Synergies in Horizontal Merger Analysis." Antitrust Law Journal 68, no.3 (2001): 685-710.

[12] Fershtman, Chaim, and Neil Gandal. "Disadvantageous Semicollusion." International Journal of Industrial Organization 12, no. 2 (1994): 141154.

[13] Friberg, Richard, Pehr-Johan Norbäck, and Lars Persson. "Ex Post Merger Evaluations and Strategic Pre-merger Investments." Journal of Competition Law and Economics 8, no. 4 (2012): 831-848. 
[14] Gugler, Klaus, and Ralph Siebert. "Market Power versus Efficiency Effects of Mergers and Research Joint Ventures: Evidence from the Semiconductor Industry." The Review of Economics and Statistics 89, no. 4 (2007): 645-659.

[15] Hernan, Roberto, Pedro L. Marin, and Georges Siotis. "An Empirical Evaluation of the Determinants of Research Joint Venture Formation." The Journal of Industrial Economics 51, no. 1 (2003): 75-89.

[16] Holmström, Bengt, and John Roberts. "The Boundaries of the Firm revisited." The Journal of Economic Perspectives 12, no. 4 (1998): 7394.

[17] Kamien, Morton I., Eitan Muller, and Israel Zang. "Research Joint Ventures and R\&D Cartels." The American Economic Review 82, no. 5 (1992): 1293-1306.

[18] Leahy, Dermot, and J. Peter Neary. "Public Policy towards R\&D in Oligopolistic Industries." The American Economic Review 87, no. 4 (1997): 642-662.

[19] Matsushima, Noriaki, Yasuhiro Sato, and Kazuhiro Yamamoto. "Horizontal Mergers, Firm Heterogeneity, and R\&D Investments." The BE Journal of Economic Analysis 8 Policy 13, no. 2 (2013): 959-990. 
[20] Phillips, Gordon M., and Alexei Zhdanov. "R\&D and the Incentives from Merger and Acquisition Activity." Review of Financial Studies 26, no. 1 (2013): 34-78.

[21] Poyago-Theotoky, Joanna. "Equilibrium and Optimal Size of a Research Joint venture in an Oligopoly with Spillovers." The Journal of Industrial Economics 43, no. 2 (1995): 209-226.

[22] Röller, Lars-Hendrik, Ralph Siebert, and Mihkel M. Tombak. "Why Firms form (or do not form) RJVS." The Economic Journal 117, no. 522 (2007): 1122-1144.

[23] Salant, Stephen W., Sheldon Switzer, and Robert J. Reynolds. "Losses from Horizontal Merger: the Effects of an Exogenous Change in Industry Structure on Cournot-Nash Equilibrium." The Quarterly Journal of Economics 98, no. 2 (1983): 185-199.

[24] Suzumura, Kotaro. "Cooperative and Noncooperative R\&D in an Oligopoly with Spillovers." The American Economic Review 82, no. 5 (1992): 1307-1320.

[25] Veugelers, Reinhilde. "Collaboration in R\&D: an assessment of theoretical and empirical findings." De Economist 146, no. 3 (1998): 419-443.

[26] Williamson, Oliver E. The economic intstitutions of capitalism. Simon and Schuster, 1985. 


\section{A Proof of Proposition 1}

Proof. The proof of the proposition proceeds in three parts.

(i) Setting $\omega=0$, in the expression for profit of an RJV insider (9) results in $\Pi_{r j v}^{i n}=\Pi_{N A}$. (ii) When $\omega=1$, from (9) we obtain

$$
\Pi_{r j v}^{i n}=\frac{(1-c)^{2} \gamma[n(\gamma-2)+\gamma]^{2}\left[(1+n)^{2} \gamma-2(n-1)^{2}\right]}{\left[8(n-1) n-2 \gamma\left(2+n+n^{2}+2 n^{3}\right)+(1+n)^{3} \gamma^{2}\right]^{2}}
$$

The profit difference $\prod_{r j v}^{i n}-\Pi_{N A}$ can be written explicitly as follows:

$$
\Pi_{r j v}^{i n}-\Pi_{N A}=\frac{2(1-c)^{2} \gamma f_{1}(n, \gamma)}{\Delta_{1}} \propto f_{1}(n, \gamma)>0
$$

where $\Delta_{1} \equiv\left[(1+n)^{5} \gamma^{3}-4(1+n)^{3}(1+n)^{2} \gamma^{2}+4 n^{2}(1+n)(4 n-1) \gamma-16(n-1) n^{2}\right]^{2}>0$. It can be shown (although tedious) that $f_{1}(n, \gamma)>0 .{ }^{25}$ (iii) For $0<\omega<1$, from (4) and (9) we obtain:

$$
\Pi_{r j v}^{i n}-\Pi_{N A}=\frac{2(1-c)^{2} f_{2}(n, \gamma, \omega)}{\Delta_{2}} \propto f_{2}(n, \gamma, \omega)>0
$$

where $\Delta_{2} \equiv\left[\gamma(1+n)^{2}-2 n\right]^{2}\left[(1+n)(\gamma+n(2-\gamma))\left((1+n)^{2} \gamma-2 n\right)\right.$ $\left.-2(n-2)(n-1)\left((1+n)^{2} \gamma-2 n\right) \omega+8 n(n-2) \omega^{2}\right]^{2}$. It can be shown by plotting on a fine grid that $f_{2}(n, \gamma, \omega)>0 .{ }^{26}$

Furthermore, notice that $\lim _{\omega \rightarrow 0^{+}} \frac{\partial}{\partial \omega}\left(\Pi_{r j v}^{i n}-\Pi_{N A}\right)=\lim _{\omega \rightarrow 0^{+}} \frac{\partial}{\partial \omega} \Pi_{r j v}^{i n}$ (as 
$\left.\frac{\partial}{\partial \omega} \Pi_{N A}=0\right)$. From (9) and after some manipulation, we obtain

$$
\lim _{\omega \rightarrow 0^{+}} \frac{\partial}{\partial \omega} \prod_{r j v}^{i n} \propto-2(-1+n)^{2} n^{3}-n(1+n)\left(-2+5 n+n^{3}\right) \gamma+(1+n)^{3}(1+(-1+n) n) \gamma^{2}>0
$$

Therefore, $\Pi_{r j v}^{i n}-\Pi_{N A}$ is non-negative.

\section{B Equilibrium expression for $W_{r j v}$}

The equilibrium expression for $W_{r j v}$, after the relevant substitutions is:

$$
\begin{aligned}
W_{r j v} & =\left(( 1 - c ) ^ { 2 } \left(n(1+n)^{2} \gamma(n(\gamma-2)+\gamma)^{2}\left((1+n)^{2}(2+n) \gamma-4 n^{2}\right)-4(n(-2+\gamma)+\gamma)\right.\right. \\
& +\left(8 n^{3}\left(-2+n^{2}\right)+4 n\left(-2+n+5 n^{2}+5 n^{3}+2 n^{4}-n^{5}\right) \gamma\right. \\
& \left.+(1+n)^{3}(4+n(-2+(-3+n) n(2+n))) \gamma^{2}\right) \omega \\
& +4\left(-16 n^{2}\left(-2+n^{2}(-4+n(2+n))\right)\right. \\
& -4 n\left(8+n\left(10+n\left(16+n\left(12+n-8 n^{2}+n^{3}\right)\right)\right)\right) \gamma \\
& +(1+n)^{2}\left(8+n\left(16+n\left(28+n\left(10+n-4 n^{2}+n^{3}\right)\right)\right)\right) \gamma^{2} \\
& \left.-2(1+n)^{4}(3+n) \gamma^{3}\right) \omega^{2}-16\left(-4 n^{2}(-3+2 n)\left(2+n^{2}\right)\right. \\
& +2 n(-8+n(-8+n(-3+n(7+(-1+n) n)))) \gamma \\
& \left.-(1+n)^{2}(-2+n(-4+n(2+n))) \gamma^{2}\right) \omega^{3} \\
& \left.\left.\left.+64(-2+n) n((-2+n) n+\gamma) \omega^{4}\right)\right)\right) \\
& /\left(2 \left((1+n)(n(\gamma-2)+\gamma)\left((1+n)^{2} \gamma-2 n\right)-\right.\right. \\
& \left.\left.2(n-2)(n-1)\left((1+n)^{2} \gamma-2 n\right) \omega+8(n-2) n \omega^{2}\right)^{2}\right)
\end{aligned}
$$




\section{Notes}

${ }^{1}$ To illustrate why precision is necessary in the RJV contract, consider an RJV relating to a single product, $X$, where one of the RJV members is a multiproduct firm with a single $R \& D$ lab for all of its lines of business. Clearly, the multiproduct firm would challenge an RJV contract that simply stated "share all R\&D related to $X$ " by claiming that any given piece of its R\&D output related to another product and so need not be disclosed within the RJV. Breadth is necessary in the RJV contract because, even if it perfectly describes previous $R \& D$ output, the participating firms have incentives to target potentially nonverifiable $R \& D$ activities.

${ }^{2}$ In the Conclusion, we discuss how this choice of modelling RJVs relates to Kamien et al.'s other case of "RJV cartelization" (i.e. co-operation between RJV insiders in the setting of R\&D but competition in outputs).

${ }^{3}$ In contrast, in the "simple" bilateral merger case where the merged firm runs a single R\&D lab, all firms are symmetric in the post-merger equilibrium; such a "simple" merger is profitable in a small region of parameter space (Matshusima et al. (2013)).

${ }^{4}$ With a homogeneous good and constant marginal (production) costs, Cournot competition seems much better suited than Bertrand to analysing $R \& D$ investments across multiple, competing firms. Moving to Bertrand competition would imply that at most one firm within the industry would make strictly positive variable profits in equilibrium. Therefore, only one firm would be prepared to make fixed-cost investments in process R\&D.

${ }^{5}$ In the working-paper version (available from the authors on request), we allow for both product differentiation and a variable degree of $R \& D$ complementarity. 
${ }^{6}$ Key papers on the choice between horizontal merger and no-agreement are Salant et al. (1983), and Deneckere and Davidson (1985). Davidson and Ferrett (2007) examine the merger/no-agreement choice in the presence of endogenous $R \& D$ investments, as do Cabolis et al. (2008) and Matsushima et al. (2013). For RJV/no-agreement comparisons, see, d'Aspremont and Jacquemin (1988), Kamien et al. (1992), Suzumura (1992), and Leahy and Neary (1997). Several papers analyse merger/acquisition decisions with endogenous R\&D but no RJV option. Bartolini (2011), Friberg et al. (2012) and Phillips and Zhdanov (2012) all have R\&D decided before merger, whereas in Bertrand et al. (2012) the merger decision precedes $\mathrm{R} \& \mathrm{D}$ determination.

${ }^{7}$ There is a parallel between our modelling and Williamson's (1985) "transaction cost" theorising on firm boundaries. Williamson (1985) assumes that integration, which gives one party formal control over both sides of a transaction, has an easier time resolving potential disputes than does a market/contracting relationship.

8 e.g., Kamien et al., 1992 (see theorem 1), Röller et al., 2007, p. 1128.

${ }^{9}$ In this sense it extends the results of Poyago-Theotoky (1995) in the context of R\&D complementarities.

${ }^{10}$ Outsiders expand their production in response to the insiders' attempts to restrict output and reach the monopoly solution. This works to undermine the profitability of horizontal mergers under Cournot competition, as highlighted by Salant et al. (1983).

${ }^{11}$ i.e. for a given vector of marginal costs across all firms.

${ }^{12}$ There are no inter-firm spillovers from R\&D. Essentially, we are concerned with cases where intra-firm R\&D spillovers (within a horizontal agreement) are significantly greater than inter-firm R\&D spillovers. Introducing inter-firm spillovers would complicate the 
analysis considerably and would dampen the main focus of the paper, which is the choice of cooperation form under the stark assumption of no spillovers so as to isolate the main drivers of this choice.

${ }^{13}$ Note that the assumption that the merged firm operates two R\&D labs is essential to have meaningful "R\&D pooling" within the merged firm. If the merged firm operated just one R\&D lab, then the equilibrium under HM would be identical to that under NA with $n-1$ firms.

${ }^{14}$ This merely makes the summations below easier to express. Often, we will refer to firm $m$ as firm 1.

${ }^{15}$ Note that we are assuming, for simplicity, that the R\&D outputs of both insiders always have the same verifiability/non-verifiability status. Thus, it is impossible, for example, for firm 1's R\&D output to be verifiable (and its contractual commitment to share $R \& D$ therefore to be enforceable) while firm 2's is not.

${ }^{16}$ In terms of the Kamien et al. (1992) taxonomy, this corresponds to the case of "RJV competition". Having the RJV insiders compete both in R\&D investments and in outputs also nicely captures the institutional fact that, in an RJV, the insiders remain independent firms (unlike following a horizontal merger).

${ }^{17}$ The second-order condition requires that $\gamma>2 n^{2} /(n+1)^{2}$, which is sufficient for $\gamma>2$ and any $n$.

${ }^{18}$ Firm $m$ 's second-order condition is $\gamma>4\left(\frac{n-1}{n}\right)^{2}$, and an outsider's is $\gamma>2\left(\frac{n-1}{n}\right)^{2}$. The former is stricter and is sufficient for $\gamma>4$ and any $n$.

${ }^{19}$ The second-order condition for an RJV firm is $\gamma>2 \omega\left(\frac{n-1}{n+1}\right)^{2}+2(1-\omega)\left(\frac{n}{n+1}\right)^{2}$, and 
for an outsider $\gamma>2\left(\frac{n}{n+1}\right)^{2}$. The former is decreasing in $\omega$, whence it coincides with the outsiders' condition. It is therefore sufficient for $\gamma>2$ and any $n$ for both to hold. Note that a sufficient condition for the relevant second-order conditions to hold across all regimes is $\gamma>4$; in what follows we impose this restriction on $\gamma$.

${ }^{20}$ Full numerical calculations (using Mathematica 8.0) are available from the authors upon request.

${ }^{21}$ As HM always dominates RJV when $n=2$ (merger to monopoly) the graphs are drawn starting at $n=3$.

${ }^{22}$ The plant/firm distinction is important in the HM game.

${ }^{23}$ There is, of course, a debate, into which we do not enter here, concerning the welfare standard that is used in practice in competition policy (e.g., social welfare, consumer surplus, or some mix of the two).

${ }^{24}$ For example, if the RJV insiders contract out their R\&D work, then the third party will require ongoing access to their accumulated R\&D stocks and technical expertise (see Bhattacharya et al. (1992) for an early analysis). This could well present similar contractual complications to those we analyse. The key point (and the key contrast with merger) is that, within an RJV, firms remain independent entities whose ultimate concern is with their own profits.

$$
\begin{aligned}
& { }^{25} f_{1}(n, \gamma)= \\
& 48(n-1)^{2} n^{4}-8 n^{2}(1+n)\left(4+n\left(-16+n\left(13-9 n+6 n^{2}\right)\right)\right) \gamma+ \\
& 4 n(1+n)^{2}(-8+n(2+n(-6+n(4+n(2+3 n))))) \gamma^{2}- \\
& 2(1+n)^{4}(4+n(-12+n(13+n(-8+5 n)))) \gamma^{3}+(1+n)^{6}(3+2(-2+n) n) \gamma^{4}>0 .
\end{aligned}
$$




$$
\begin{aligned}
& { }^{26} f_{2}(n, \gamma, \omega)= \\
& 2\left(2 n(-1+\gamma)+\gamma+n^{2} \gamma\right)^{2}\left(\gamma^{3}+3 n \gamma^{3}+n^{6}(-2+\gamma)^{2}(1+\gamma)+2 n^{3} \gamma\left(2-5 \gamma+\gamma^{2}\right)+\right. \\
& \left.n^{2} \gamma\left(-4-5 \gamma+3 \gamma^{2}\right)+n^{4}\left(4+12 \gamma-8 \gamma^{2}+3 \gamma^{3}\right)+n^{5}\left(-8+4 \gamma-6 \gamma^{2}+3 \gamma^{3}\right)\right) \omega+ \\
& \left((-6+\gamma) \gamma^{4}-4 n^{10} \gamma^{2}\left(2-3 \gamma+\gamma^{2}\right)+2 n \gamma^{3}\left(8-6 \gamma+3 \gamma^{2}\right)+4 n^{2} \gamma^{2}\left(4+10 \gamma^{2}+3 \gamma^{3}\right)+\right. \\
& 16 n^{3} \gamma\left(-4-3 \gamma-12 \gamma^{2}+11 \gamma^{3}\right)-2 n^{9} \gamma\left(-16+40 \gamma-20 \gamma^{2}+2 \gamma^{3}+\gamma^{4}\right)- \\
& 16 n^{7} \gamma\left(8-8 \gamma+12 \gamma^{2}-10 \gamma^{3}+3 \gamma^{4}\right)+n^{4}\left(32+240 \gamma+128 \gamma^{2}-488 \gamma^{3}+296 \gamma^{4}-42 \gamma^{5}\right)+ \\
& n^{8}\left(-32+112 \gamma-64 \gamma^{2}+46 \gamma^{4}-15 \gamma^{5}\right)-4 n^{5}\left(32+56 \gamma-128 \gamma^{2}+150 \gamma^{3}-80 \gamma^{4}+21 \gamma^{5}\right)- \\
& \left.4 n^{6}\left(-32+40 \gamma-110 \gamma^{2}+113 \gamma^{3}-67 \gamma^{4}+21 \gamma^{5}\right)\right) \omega^{2}+ \\
& 2(-1+n)\left(2 n^{8}(-2+\gamma)^{2} \gamma^{2}+\gamma^{4}+3 n \gamma^{3}(8+\gamma)-n^{2} \gamma^{2}\left(40-84 \gamma+\gamma^{2}\right)+\right. \\
& n^{7} \gamma\left(-32+36 \gamma-28 \gamma^{2}+9 \gamma^{3}\right)-n^{3} \gamma\left(32+128 \gamma-100 \gamma^{2}+13 \gamma^{3}\right)+ \\
& n^{4}\left(16+176 \gamma-108 \gamma^{2}+32 \gamma^{3}-15 \gamma^{4}\right)+n^{5}\left(-48-64 \gamma+28 \gamma^{2}-32 \gamma^{3}+\gamma^{4}\right)+ \\
& \left.n^{6}\left(32-16 \gamma+76 \gamma^{2}-44 \gamma^{3}+13 \gamma^{4}\right)\right) \omega^{3}- \\
& 32(-2+n)^{2} n^{2} \gamma\left(n^{2}(-2+\gamma)+\gamma+2 n \gamma\right) \omega^{4} .
\end{aligned}
$$




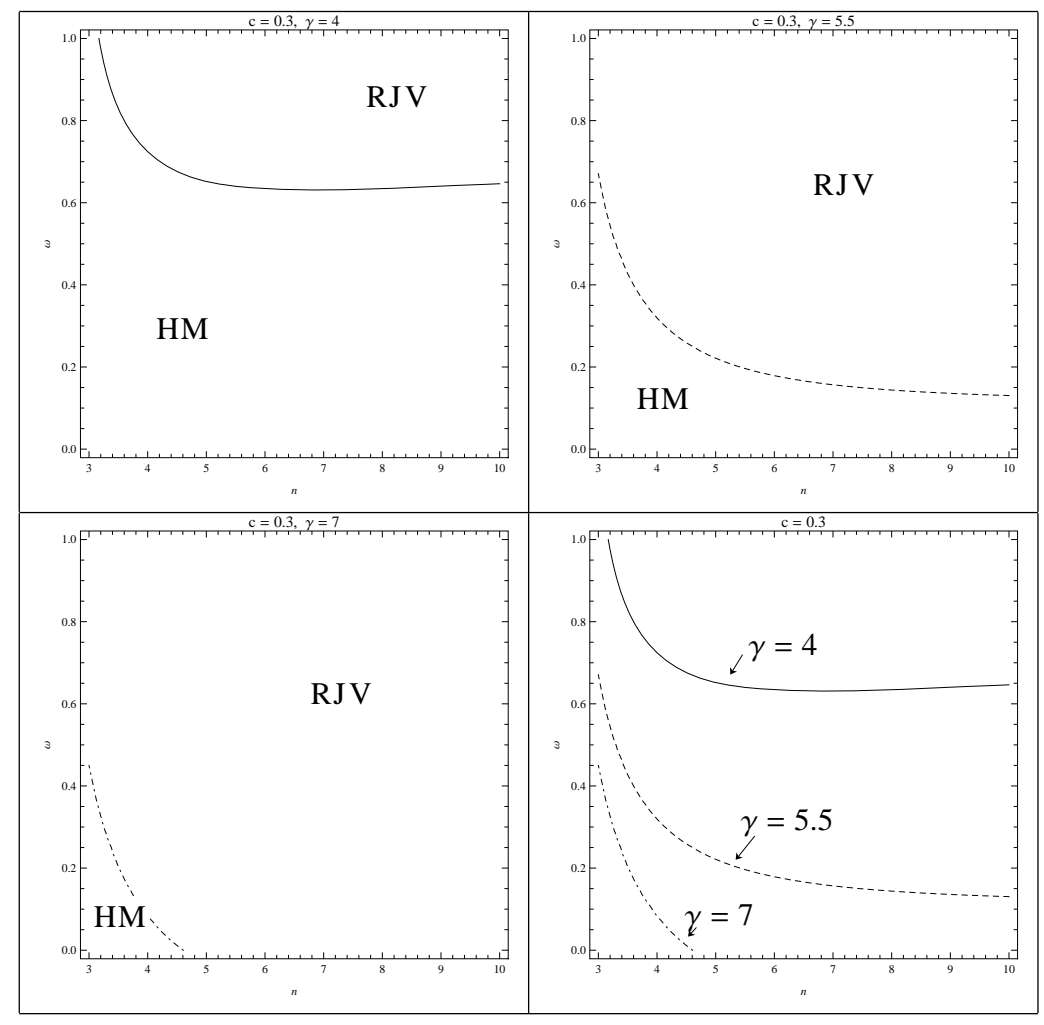




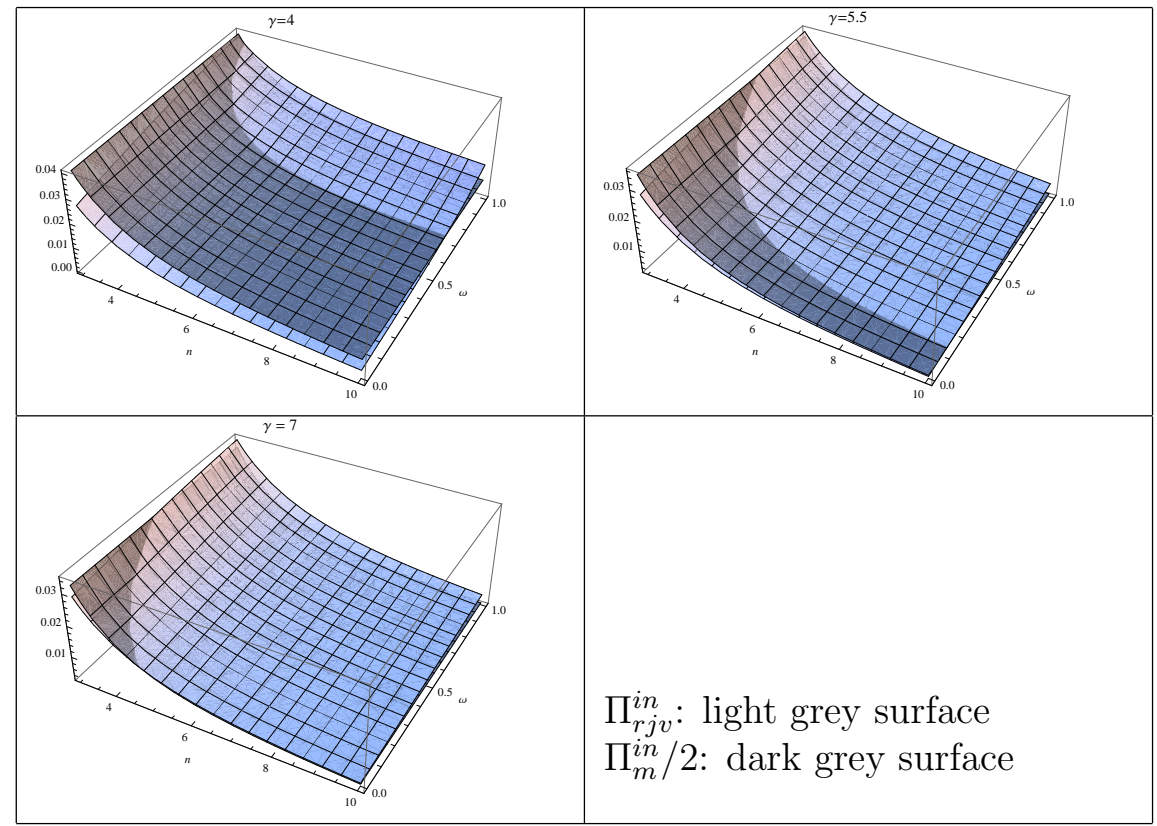




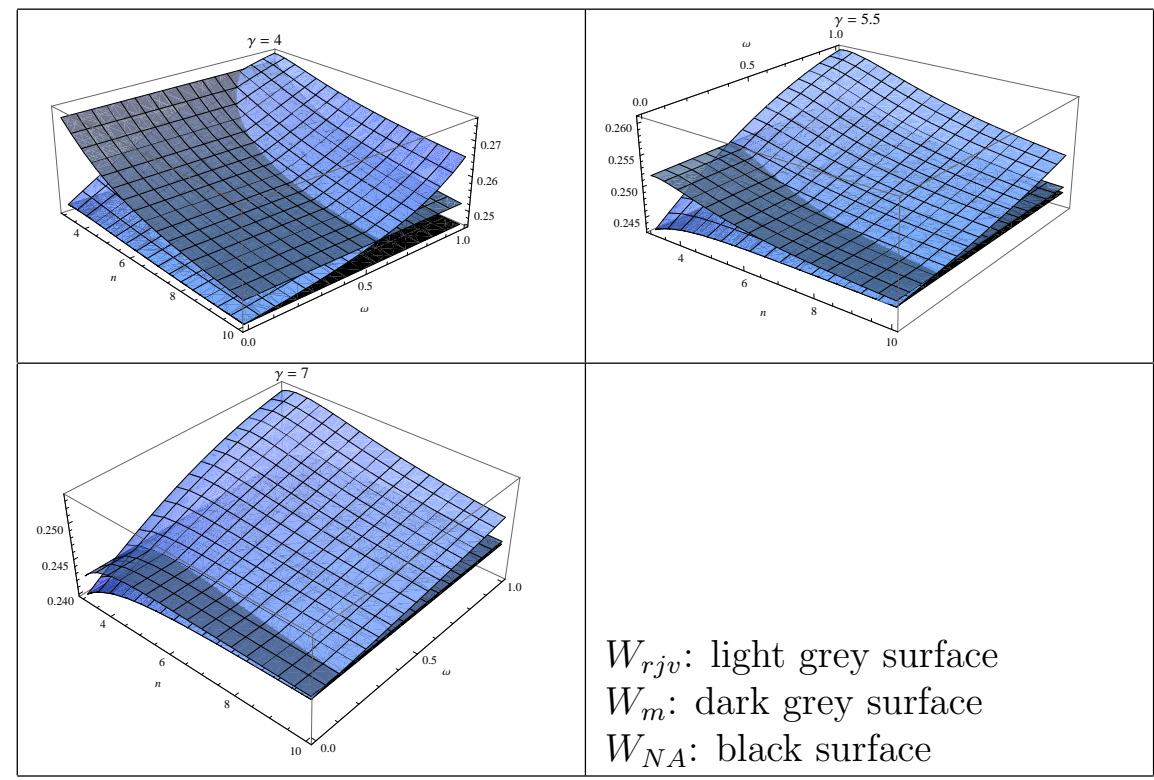




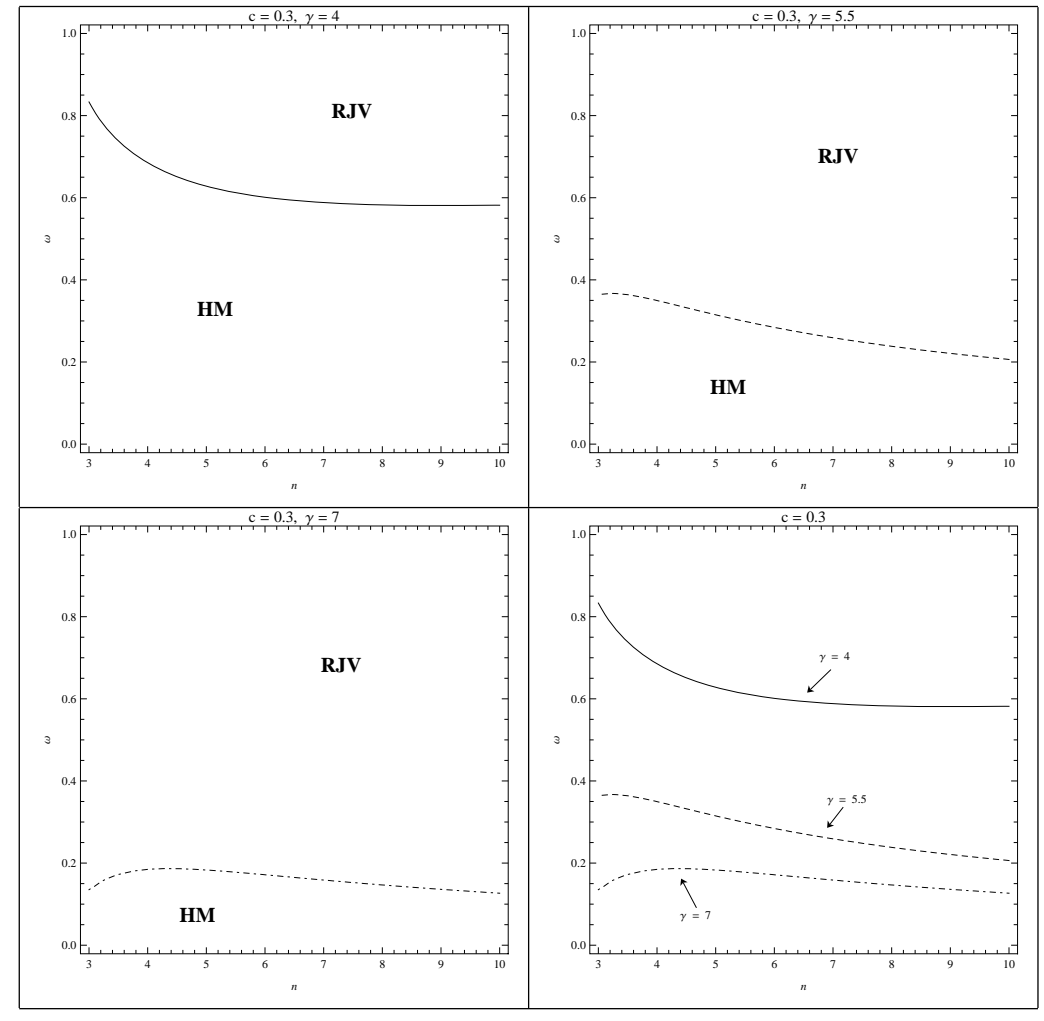




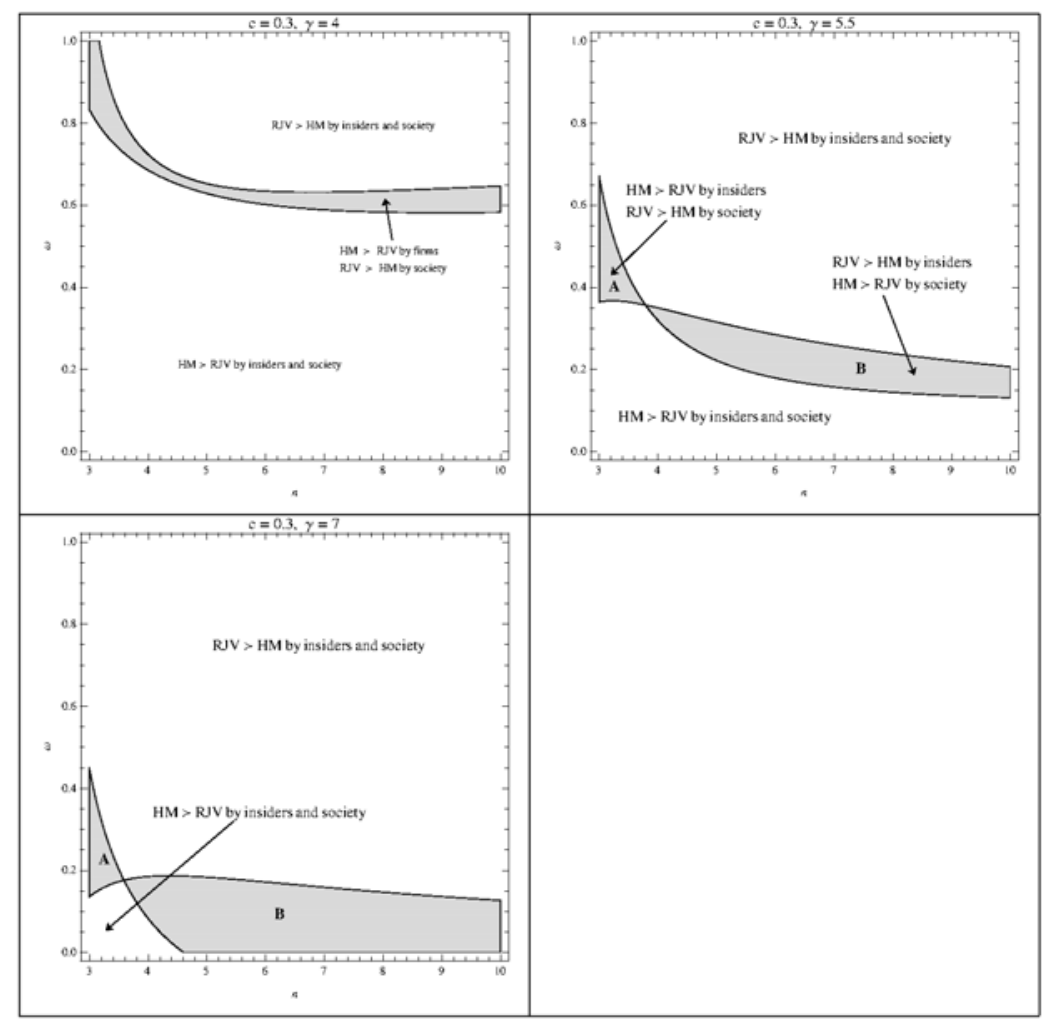

